\title{
Prevalence of microalbuminuria in hypertension monitored in primary care
}

\author{
Elena ARDELEANU ${ }^{1}$, Maria DOROBANTU² ${ }^{2}$, Roxana DARABONT² ${ }^{2}$ Daniel LIGHEZAN ${ }^{3}$, Rodica LIGHEZAN ${ }^{4}$, \\ Dacian PURCARITA ${ }^{1}$, Alexandra DELEANU ${ }^{5}$, Daniela GURGUS ${ }^{1}$, Patricia NICOLA ${ }^{1}$, Shamsa BAAJ ${ }^{1}$ \\ ${ }^{1}$ Discipline of Family Medicine, „Victor Babes“ University of Medicine and Pharmacy, Timisoara \\ ${ }^{2}$ Cardiology Clinic, “Floreasca” Emergency Hospital, „Carol Davila“ University of Medicine and \\ Pharmacy, Bucharest \\ ${ }^{3}$ Discipline of Semiology, „,Victor Babes" University of Medicine and Pharmacy, Timisoara \\ ${ }^{4}$ Discipline of Parasitology, „Victor Babes“ University of Medicine and Pharmacy, Timisoara \\ ${ }^{5}$ Discipline of Gastroenterology, UMF „Victor Babes“, Timisoara
}

\begin{abstract}
The objectives of the study were to evaluate the prevalence of microalbuminuria (MAU) in patients with hypertension, monitored in primary care and to analyse the correlation between MAU, risk factors and associated parameters.

Material and methods. During 2010-2014 we evaluated a number of 910 patients from 19 family medicine offices of Timiş County. The general practitioners took a standardized history, performed a physical examination, measured height, weight, blood pressure, ABPM and heart rate, calculated body mass index and tested urine for MAU with Arkray test strips. The patients with hypertension and MAU were referred to diagnosis centres where they underwent echocardiography.

Results. After exclusion of patients with a history of renal disease and diabetes, MAU was present in 61 cases, $7.1 \%$. The mean age of the MAU positive patients was $56 \pm 13.1$ years, ranging from 29 to 79 . The duration of hypertension was under 5 years in $4(2.44 \%)$ patients, between $5-10$ years in $35(57.3 \%)$ and over 10 years in 22 (36\%) Six patients with MAU (9.83\%) had mild hypertension, 25 (40.9\%) moderate and $30(49.1 \%)$ severe hypertension. LVMI was $125 \pm 28 \mathrm{~g} / \mathrm{m} 2$ in the MAU absent group and $157 \pm 56 \mathrm{~g} /$ $m 2$ in the MAU present group $(<0.04)$. A stepwise logistic regression analysis showed significant positive effects of $24 \mathrm{~h}$ systolic blood pressure, weight and LVH ( $p<0.001$ for all comparisons) on MAU. No other variable had a significant predictive effect on the presence or absence of $M A U$.

Conclusions. In patients with essential hypertension MAU was present in $7.1 \%$, with a higher prevalence in uncontrolled than in controlled hypertension. MAU was associated with high blood pressure levels, obesity and LVH.
\end{abstract}

Keywords: hypertension, microalbuminuria, primary care 


\section{INTRODUCTION}

The European Society of Cardiology Hypertension Guidelines 2013 outline that it becomes more and more important to determine the target organ damage secondary to hypertension (1). The presence of MAU in patients with essential hypertension is related to cardiovascular morbidity and mortality, independent of other well-known risk factors. Microalbuminuria, in addition to being an early sign of kidney damage, is often found in patients with essential hypertension. Even very low levels of microalbuminuria strongly correlate with CV risk, independent of the presence of other risk factors. Increased microalbuminuria indicates endothelial dysfunction and predicts end-organ damage, cardio- and cerebrovascular events and death $(2,3)$. European guidelines recommend screening for microalbuminuria in patients with hypertension. Available tests for screening microalbuminuria as deep sticks are sensitive and accessible. Early identification of high-risk patients through detection of MAU allows selection of an aggressive treatment to slow disease progression. Antihypertensive agents providing angiotensin II blockade are recommended for the treatment of hypertensive patients with $M A U$, as they assure effective reduction of MAU, blood pressure, and long-term prevention of CV events beyond blood pressure reduction. In this way a substantially reduced burden on healthcare resources can be obtained (4).

\section{THE OBJECTIVES OF THE STUDY}

- To evaluate the incidence of microalbuminuria in controlled and uncontrolled hypertension in primary care

- To analyse the association between microalbuminuria, risk factors and other clinical data.

\section{MATERIAL AND METHODS}

We evaluated during 2010-2014 a total number of 910 hypertensive patients from 19 family medicine offices of Timiş County. Uncontrolled hypertension was defined as blood pressure $\geq 140 / \geq 90 \mathrm{mmHg}$, when subjects reported lifestyle changes and medication consisting of $\geq 1$ antihypertensive drug. All family doctors implied in the study were instructed to use the same method of BP measurement and patient evaluation.

The general practitioners performed the history, the physical examination and calculated the body mass index (BMI). A spot urine sample was tested for MAU at the family doctor's office with Arkray test strips, that provide the following readings for urinary albumin: negative, $\geq 10 \mathrm{mg} / \mathrm{L}, \geq 30 \mathrm{mg} / \mathrm{L}, \geq 80 \mathrm{mg} / \mathrm{L}$ and $\geq 150 \mathrm{mg} / \mathrm{L}$. Creatinine readings were for concentrations of $10 \mathrm{mg} / \mathrm{dl}, 50 \mathrm{mg} / \mathrm{dl}, 100 \mathrm{mg} / \mathrm{dl}, 200 \mathrm{mg} / \mathrm{dl}$ and $300 \mathrm{mg} / \mathrm{dl}$ (Fig. 1). Albumin creatinine ratio was calculated by intersection of their values (Fig. 2). The patients with hypertension and microalbuminuria were referred by their general practitioners to a diagnosis centre, where they underwent echocardiography. Only patients with complete measurements were included in the study.

\section{STATISTICAL ANALYSIS}

All the statistical analyses were performed using the software Stata 9.2. Data were presented as frequencies and percentages for qualitative variables and as mean \pm SD for quantitative variables. Differences between groups of variables were assessed with the Pearson $x^{2}$ for qualitative variables and the Student $t$ test for quantitative data. The independent variables

\begin{tabular}{|c|c|c|c|c|c|c|c|}
\hline Name & Time & \multicolumn{6}{|c|}{ Test results interpretation } \\
\hline \multirow{2}{*}{ Creatinine } & \multirow{2}{*}{$60 \mathrm{sec}$} & 10 & \multirow{2}{*}{$(\mathrm{mg} / \mathrm{dl})$} & 50 & 100 & 200 & 300 \\
\hline & & & & & & & \\
\hline \multirow{2}{*}{ Albumine } & \multirow{2}{*}{$60 \mathrm{sec}$} & 10 & \multirow[b]{2}{*}{$(\mathrm{mg} / \mathrm{L})$} & 30 & 80 & 150 & \\
\hline & & & & & & & \\
\hline Calibration & - & & & & & & \\
\hline
\end{tabular}

FIGURE 1. Interpretation of albumin and creatinine concentrations by the coloration of Arkray test strips 


\begin{tabular}{|c|c|c|c|c|c|}
\hline \multirow{2}{*}{$\begin{array}{c}\text { Albumin } \\
\mathrm{mg} / \mathrm{L}\end{array}$} & \multicolumn{5}{|c|}{ Creatinine $\mathrm{mg} / \mathrm{dl}$} \\
\cline { 2 - 6 } & 10 & 50 & 100 & 200 & 300 \\
\hline 10 & Re-analysis & Normal & Normal & Normal & Normal \\
\hline 30 & +2 & +1 & +1 & Normal & Normal \\
\hline 80 & +2 & +1 & +1 & +1 & Normal \\
\hline 150 & +2 & +2 & +1 & +1 & +1 \\
\hline
\end{tabular}

FIGURE 2. Albumin creatinin ratio: normal range, $+1(\mathrm{MAU})$ and +2 (macroalbuminuria)

with $\mathrm{p}<0.05$, were considered as having statistical significance.

\section{RESULTS}

The blood pressure values of controlled and uncontrolled hypertension patients are presented in Fig. 3. After exclusion of cases with a history of renal disease and with diabetes, MAU remained present in 61 cases $(13.41 \%)$, of which $22(4.3 \%)$ with controlled hypertension and 39 (9.11\%) with uncontrolled (Fig. 4).

The characteristics of patients with and without MAU are presented in the Table 1.

Concerning gender repartition of microabuminuria patients, $44.26 \%$ were male and $55.73 \%$ female (Fig. 5).

The mean age of the patients was $56 \pm 13.1$ years, ranging from 29 to 79, the majority being between 50 and 60 years. There were 3 cases (4.9\%) with MAU under 40 years, 6 cases $(9.8 \%)$ between $40-50$ years, 31 cases $(50.8 \%)$ between $50-60$ years and 21 cases (34.4\%) over the age of 60 years old. Age groups of patients with MAU are presented in Fig. 6.

The evolution in time of hypertension showed: a hypertension duration under 5 years in $2.44 \%$, between $5-10$ years in $57.3 \%$ and over 10 years in $36 \%$ (Fig. 7 ).
The severity degree of hypertension was evaluated after the recommendations of the Hypertension Guidelines of the European Society of Cardiology published in 2013 (Fig. 8).

Depending on the hypertension profile, the patients were divided in two groups: the dipper group of 27 (44.2\%) and the non-dipper group, consisting of 34 patients (45.8\%), whose hypertension fell less than $10 \%$ during the night time (Fig. 9).

Concerning the cardiovascular risk of the patients that associated MAU, 47 cases $(77.8 \%)$ had a high and very high risk, 12 cases (19.6\%) a moderate risk and 2 cases (3.2\%) a low $\mathrm{CV}$ risk (Fig. 10).

The main cardiovascular risk factors among hypertensive subjects with MAU were: physical inactivity in $60.6 \%$, smoking in $21.3 \%$, a family history of premature cardiovascular disease in $24.5 \%$, obesity in $40.98 \%$, lipid disorders in $50.8 \%$ and metabolic syndrome in $52.4 \%$. Left ventricular mass index was higher in MAU patients than in normal buminuria hypertensives.

A stepwise logistic regression with MAU as the dependent variable and as independent variables age, gender, height, weight, BMI, $24 \mathrm{~h}$ systolic and diastolic blood pressure, left ventricular hypertrophy, showed significant positive effects of $24 \mathrm{~h}$ systolic blood pressure

TABLE 1. Characteristics of patients with and without MA

\begin{tabular}{|l|c|c|c|}
\hline Characteristics & MAU absent; $\boldsymbol{n = 8 7}$ & MAU present; $\boldsymbol{n}=\mathbf{6 1}$ & $\boldsymbol{p}$ \\
\hline Gender: male & $42 \%$ & $58 \%$ & NS \\
\hline Age (years) & $52 \pm 7$ & $49 \pm 8$ & NS \\
\hline Height $(\mathrm{cm})$ & $166 \pm 9$ & $168 \pm 10$ & NS \\
\hline Weight $(\mathrm{kg})$ & $77 \pm 14$ & $86 \pm 16$ & $<0.05$ \\
\hline BMI $\left(\mathrm{kg} / \mathrm{m}^{2}\right)$ & $27.5 \pm 4.5$ & $31.9 \pm 8.7$ & $<0.05$ \\
\hline Plasma creatinine $(\mathrm{mg} / \mathrm{dl})$ & $0.8 \pm 0.03$ & $0.8 \pm 0.04$ & $\mathrm{NS}$ \\
\hline Average $24 \mathrm{~h} \mathrm{BP}(\mathrm{mmHg})$ & $131 / 82 \pm 13 / 8$ & $149 / 86 \pm 14 / 10$ & $<0.001$ \\
\hline Left ventricular mass $(\mathrm{g})$ & $216 \pm 53$ (men) & $266 \pm 70$ (men) & $<0.05$ \\
\cline { 2 - 5 } & $170 \pm 50$ (women) & $209 \pm 61$ (women) & $<0.05$ \\
\hline
\end{tabular}

Data are expressed as mean $\pm \mathrm{SD}, \mathrm{BP}=$ blood pressure 


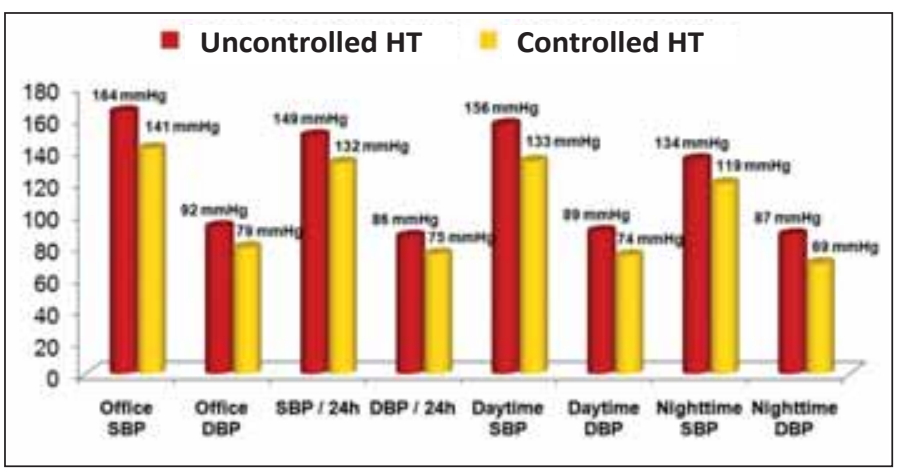

FIGURE 3. Blood pressure values in controlled and uncontrolled hypertension

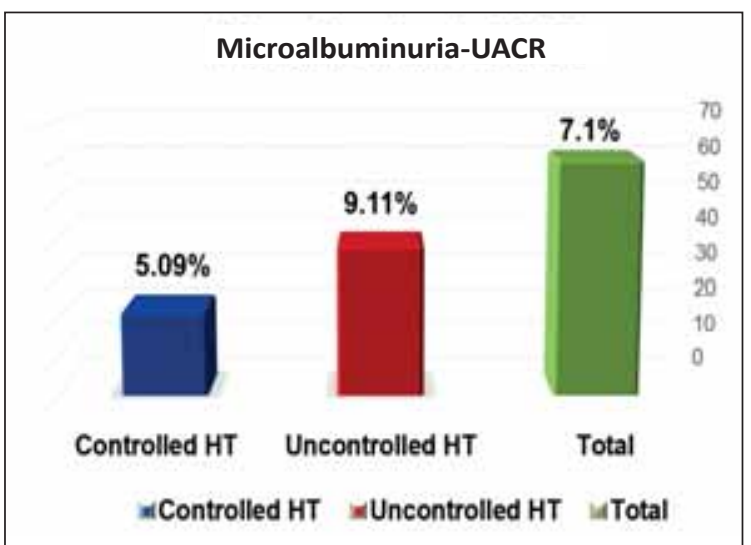

FIGURE 4. MAU determined by UACR in controlled and uncontrolled hypertension

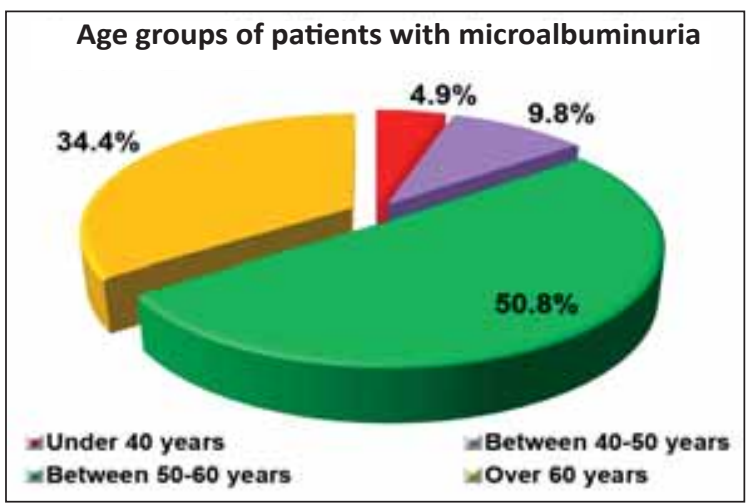

FIGURE 6. Age groups of patients with MAU

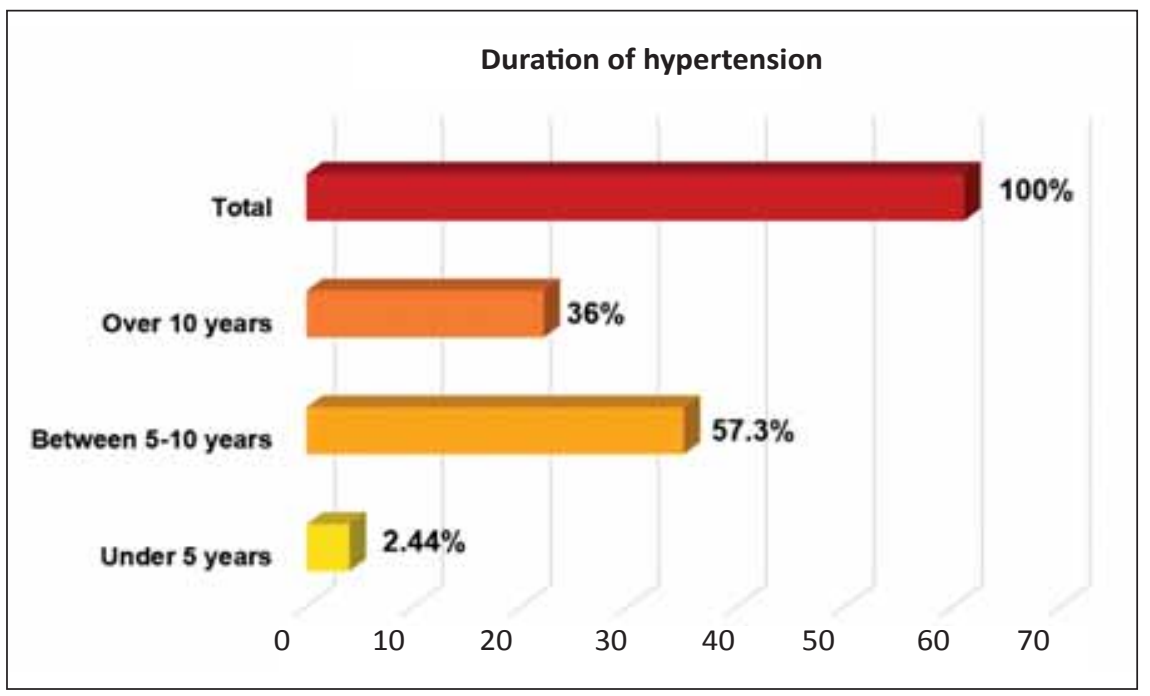




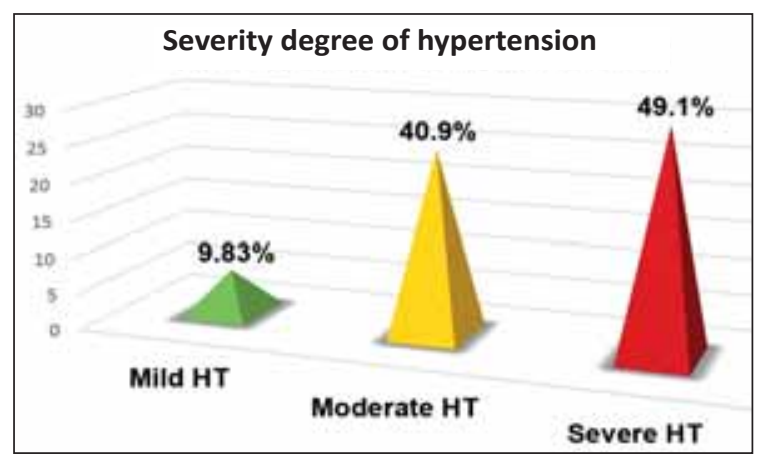

FIGURE 8. Severity degree of hypertension with MAU

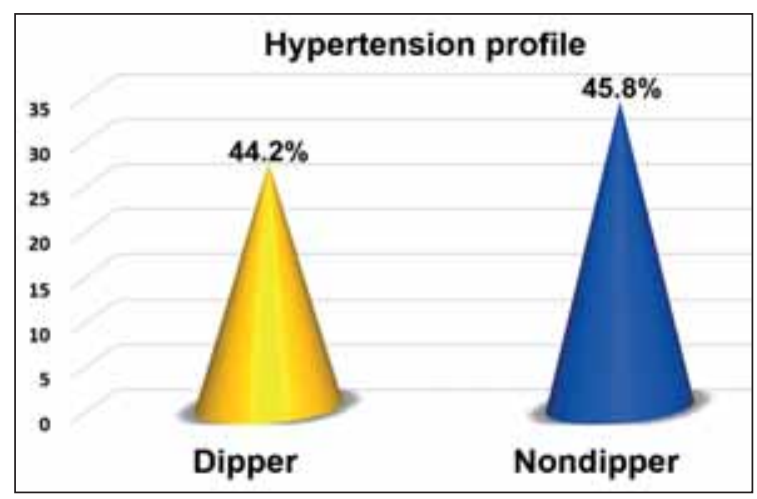

FIGURE 9. Hypertension's profile in patients with MAU

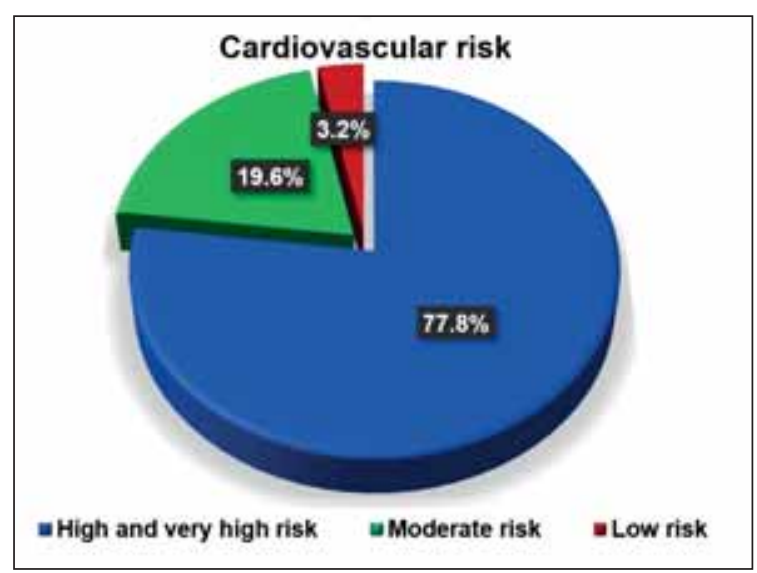

FIGURE 10. Cardiovascular risk of hypertension associating MAU

$(p<0.0001)$, weight $(p<0.001)$ and LVH $(p<0.001)$. No other variables had a significant predictive effect on the presence or absence of MAU.

\section{DISCUSSIONS}

Urine excretion of albumin is highly variable, from nondetectable to milligrams and even grams of albumin. Microalbuminuria is defined as albumin excretion of 30 to $300 \mathrm{mg} /$ day (5). Microalbuminuria is highly prevalent in hypertensive and diabetic populations, form 10 to
$40 \%$. Microalbuminuria also is found in 5 to $7 \%$ healthy individuals. The excretion of albumin in the urine is related to the risk to develop cardiovascular disease (6). The International Survey Evaluating microalbuminuria by cardiologists in patients with hypertension (i-SEARCH) was undertaken in 26 countries around the world in a total of 1,750 sites to provide epidemiological data on the prevalence of MAU and its associations with established cardiovascular risk markers and disease.

Our study evaluated a population of hypertensive patients monitored by general practitioners. We found a total prevalence of MAU of 7.1\% that was lower in controlled hypertension than in uncontrolled hypertension, dependent on- the level of $24 \mathrm{~h}$ average systolic blood pressure, bodyweight and left ventricular hypertrophy (7).

We recorded as in the SEPHAR II survey only in a minority of cases MAU, as the most important part of hypertensive patients didn't present this subclinical organ damage $(7,8)$.

Many studies investigated the relationship between the number of cardiovascular comorbidities and the presence of MAU in hypertension. The prevalence of MAU increased from $54 \%$ in patients without cardiovascular comorbidities to $74 \%$ in the presence of more than 3 comorbidities. The conclusion is that in hypertensive patients at high cardiovascular risk, the prevalence and extent of MAU increases with the number of comorbidities $(8,9)$.

Our data confirm previous studies that have demonstrated a relationship between albumin excretion rate and the level of systolic blood pressure. As showed, most of the patients had severe hypertension with high cardiovascular risk. The positive relation of MAU to bodyweight is demonstrated in some other surveys (10). Many clinical trials have not been able to demonstrate a significant relationship between MAU and age, aspect that requires further confirmation (11).

As in other studies, we found that LV mass is increased in patients with MAU and might quite well account for the observed increase in cardiovascular morbidity and mortality in patients with MAU.

\section{CONCLUSIONS}

Early signs of hypertensive nephropathy as MAU can be easily detected by general practitioners with test strips. 
Microalbuminuria was present in $7.1 \%$ of patients with essential hypertension, with a higher prevalence in uncontrolled than in controlled hypertension.

MAU was associated with high blood pressure levels, obesity and an increase in left ventricular mass.
Microalbuminuria reflects a state of pathophysiologic vascular dysfunction that makes an individual susceptible to organ damage.

Further studies are needed to elucidate the underlying links between MAU and left ventricular structure.

\section{REFERENCES}

1. Mancia G. 2013 ESH/ESC Guidelines for the management of arterial hypertension. J Hypertens. 2013.31:1281-1357

2. Cerasola G., Cottone S., Mule G. et al. Microalbuminuria, renal dysfunction and cardiovascular complication in essential hypertension. J Hypertens. 1996; 14:915-20.

3. Redon J., Liao Y., Lozano J.V., et al. Factors related to the presence of microalbuminuria in essential hypertension. Am J Hypertens. 1994; 7:801-7

4. Palatini P., Graniero G.R., Mormino P. et al. Prevalence and clinical correlates of microalbuminuria in stage I hypertension. Results from the Hypertension and Ambulatory Recording Venetia Study
(HARVEST Study). Am J Hypertens. 1996; 9: 334-41

5. Sarafidis P., Bakris G. Microalbuminuria and chronic kidney disease as risk factors for cardiovascular disease. Nephrol Dial Transplant. 2006; 21:2366-74

6. Donaire G., Ruilope L. Cardiovascular and renal links along the cardiorenalcontinuum. Int J of Nephrolog. 2011; 34: 9757-83

7. Ardeleanu E., Barbu A., Gurgus D. et al. Management of Resistant Hypertension in Primary Care. Journal of Hypertension. 2014. Vol.32, e-Supplement1. e492. PP.29.34

8. Dorobanțu M., Darabonț R., Ghiorghe S. et al. Profile of the Romanian Hypertensive Patient Data from SEPHAR II Study.
Romanian Journal of Internal Medicine. 2012; 50:4,285-296

9. Dorobanțu M., Darabont R., Ghiorghe S. et al. Hypertension prevalence and control in Romania at a seven-year interval. Comparison of SEPHAR I and II surveys. Journal of Hypertension. 2014; Vol. 32, 1: p. 39-47.

10. Bramlage P., Pittrow D., Wittchen HU, et al. Hypertension in overweight and obese primary care patients is highly prevalent and poorly controlled. J Am Hypertens. 2004; 17:904-10.

11. Moser M., Setaro J.F. Resistant of Difficult-to-Control Hypertension. The New England Journal of Medicine. 2006; 355:385-92 